\title{
Effect of sediment load reduction in tidal entrance channels
}

\author{
A. J. Mehta ${ }^{1}$, Y. P. Khare ${ }^{2}$ \& K. Park ${ }^{3}$ \\ ${ }^{1}$ Nutech Consultants, Inc., Gainesville, USA \\ ${ }^{2}$ Department of Agricultural and Biological Engineering, \\ University of Florida, USA \\ ${ }^{3}$ St Johns River Water Management District, USA
}

\begin{abstract}
A matter of concern in water management is that the removal of suspended sediment accompanying the withdrawal of freshwater from a stream for commercial or recreational uses may induce long-term morphologic changes in the downstream estuary. To calculate the change in the cross-sectional area due to sediment load reduction in the estuarine entrance channel, the well-known method of Escoffier is used, and, separately, the adaptation time is estimated. The analysis is applied diagnostically to the Matanzas Inlet on the Atlantic Coast of Florida. It is a useful tool for a first-order estimation of the impact of withdrawal at tidal entrances where data for more accurate process-based modeling are scarce.

Keywords: Matanzas Inlet, method of Escoffier, sediment transport, tidal inlet, water management
\end{abstract}

\section{Introduction}

High water consumption usually requires water management agencies to consider long-term impacts of the withdrawal of freshwater from riverine streams. For example, the state of Florida's Minimum Flows and Levels statute mandates a scientific assessment of the likely downstream effects of reduction in the sediment load accompanying freshwater withdrawal (Neubauer et al. [1]). A significant reduction in high stream-sediment load may have measurable effects on the morphology of urbanized entrance channels where marine infrastructure can be dense. A method to calculate the cross-sectional area of entrance channels in sedimentary equilibrium was developed by Escoffier [2]. We will follow that 
approach to consider the likely effect of sediment load reduction on the crosssection, and calculate the time for adaptation from the initial to the final equilibrium cross-section. Lastly, we will diagnostically apply the method to Matanzas Inlet on the Atlantic Coast of Florida (Fig. 1).

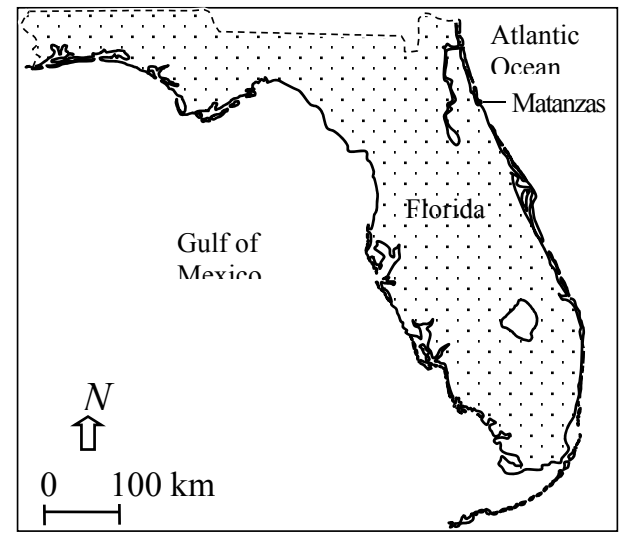

Figure 1: Map of Florida showing Matanzas Inlet on the Atlantic Coast.

\section{Entrance cross-section}

In general, the variation of area $A(x)$ of estuaries in sedimentary equilibrium can be approximated as

$$
A(x)=A_{0} e^{-\Xi x}
$$

in which $A_{0}$ is the area at the seaward end, $x=0$, of the estuarine entrance and $\Xi$ defines the rate of convergence of $A$ (Fig. 2). For entrances of short length $x_{L}$, we will assume that the mean depth is reasonably represented by $h_{0}=A_{0} / B_{0}$, often the only available depth, with $B_{0}$ the width at the mouth. From Eq. (1) the mean area $A_{L}$ is

$$
A_{L}=\frac{A_{0}}{\Xi x_{L}}\left(1-e^{-\Xi x_{L}}\right)
$$

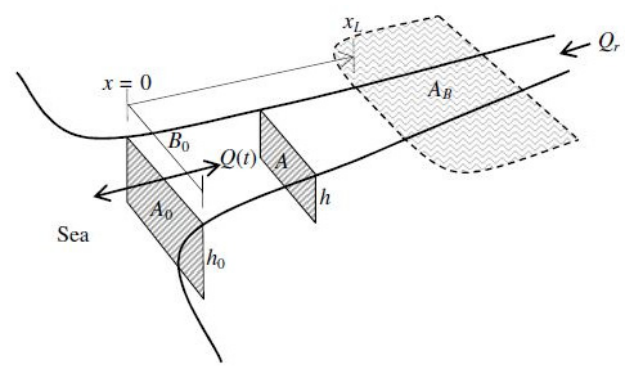

Figure 2: Estuary entrance definition, characteristic dimensions and parameters. 
In general, $h_{0}$ increases with $A_{L}$ and influences bed resistance (e.g. O'Brien and Dean [3]). This increase is evident in Fig. 3, which includes entrances from both, the Atlantic and the Gulf of Mexico, coasts of Florida. As $A_{L}$ increases the width increases more readily than $h_{0}$, which is limited by the scouring ability of the tidal stream-power. "Small" and "large" entrances are notionally defined with respect to area and separated at $A_{L}=20 \mathrm{~m}^{2}$. The dependence of $h_{0}$ on $A_{L}$ is less sensitive at wide entrances than at narrow ones. Moveable-bed model data are included for completeness. The mean trends are given by

$$
h_{0}=p A_{L}^{m}
$$

with $p$ and $m$ equal to 0.224 and 0.500 for small entrances, respectively, and 0.369 and 0.333 for large entrances. From Eq. (3)

$$
\frac{d A_{L}}{A_{L}}=\frac{1}{m} \frac{d h_{0}}{h_{0}}
$$

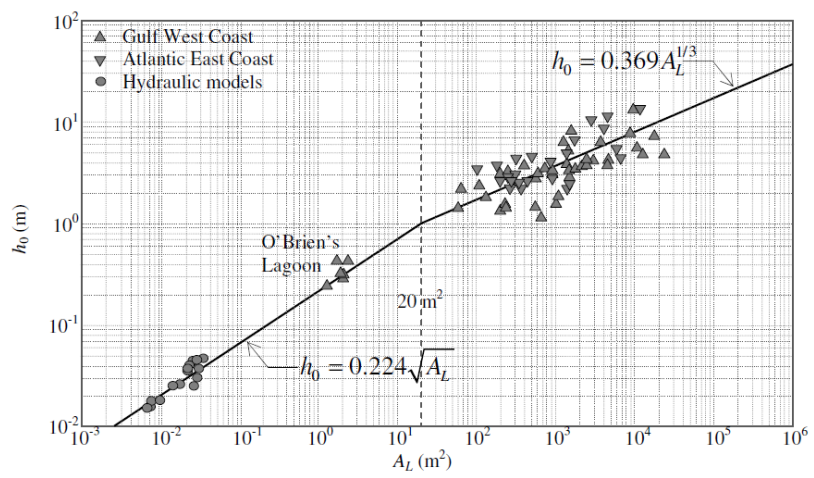

Figure 3: Dependence of $h_{0}$ with $A_{L}$ at entrance channels in Florida based on data from Powell et al. [4]. O’Brien's Lagoon vanished during 1980s. Physical model data are from Bruun [5].

Thus, as $\mathrm{m}$ is smaller $(=1 / 3)$ at large entrances compared to small $(=1 / 2)$, area change (relative to original) at large entrances is more susceptible to depth change (relative to original) than at small entrances.

\section{Sediment load}

Following Powell et al. [4], we will relate the volumetric bed-material load $Q_{s}$ to water discharge $Q$ by the well-known Einstein-Brown formula for sand transport (e.g. Julien [6]) as applied to channels in sedimentary equilibrium. This formula can be expressed as

$$
q_{s}=K \frac{q^{6}}{h^{7}} ; \quad K=\frac{20 g n^{6}}{9 v(s-1)^{2}}
$$

where at any distance $x, q_{s}=Q_{s} / B$ is the unit sediment load, $q=Q / B$ is the unit discharge, $B$ is the channel width, $h$ is the water depth, $s$ is the particle specific 
gravity, $v$ is the kinematic viscosity of water and $n$ is Manning's bed resistance coefficient representing energy loss distributed over the channel.

Estuaries that generally conform to Eq. (1) are considered to be in sedimentary equilibrium over a suitably long duration relative to tidal period $T$. At every $x$ the tide-mean area $A(x)$ bears a fixed relationship with the mean tidal prism $P(x)$ raised to some power (close to unity) (O'Brien [7]). From Hughes [8] and Powell et al. [4] among others, this relationship based on Eq. (5) is

$$
A=\Omega P^{6 / 7}
$$

where

$$
P=\frac{2 U A}{C_{k} \sigma} ; \quad \Omega=\left(K \frac{C_{k}^{6} \sigma^{6}}{\pi^{6} p^{2} \alpha_{s} Q_{s}}\right)^{1 / 7} A^{4 / 21}
$$

In Eq. (7), $C_{k}(=0.86)$ accounts for the effect of overtide, which increases the prism above its value obtained by assuming the discharge to be sinusoidal. The fraction $\alpha_{s}$ defines reduction of sediment load, and $\alpha_{\mathrm{s}} Q_{s}$ is the load in transport. As $\alpha_{s}$ becomes smaller than $1, \Omega$ increases and, for a given $P, A$ increases as well. If we hypothetically consider the width to remain constant, sediment load reduction will erode the bed, i.e. increase the channel depth. This is evident from the dependence of $q_{s}$ and $q$ on $\mathrm{h}$ in Eq. (5). The rate of expansion of the cross-section by erosion will decrease gradually from maximum at the onset of adaptation to nil when the new equilibrium area is achieved.

Equation (6) sets the sediment transport requirement in the equilibrium estuary. To address its range of applicability, in Fig. 4 data are given from nine estuaries. Overall, given $A$ in $\mathrm{m}^{2}$ and $P$ in $\mathrm{m}^{3}, 0.0015$ is a mean equilibrium value of $\Omega$ in the absence $\left(\alpha_{s}=1\right)$ of load reduction. For individual channels the exponent tends to differ from 6/7. Equation (6) has been used extensively for entrance channels, with the actual value of the exponent ranging between about 0.95 to 1.05 depending on the coast, e.g. Atlantic or Gulf, and whether the channel is natural or modified by jetties or dredging (Powell et al. [4]).

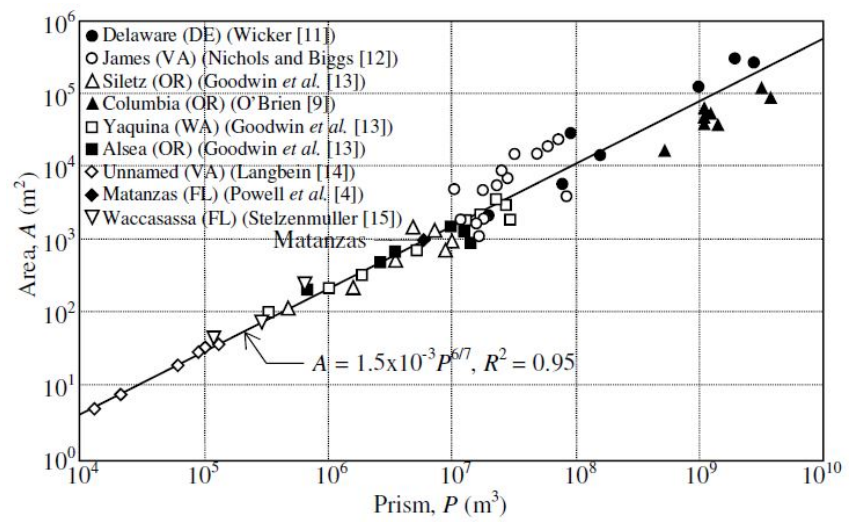

Figure 4: Cross-sectional area against mean tidal prism from nine U.S. estuaries, based on data compiled by Alkhalidi [16] and Powell et al. $[4]$. 
Equations (6) and (7) provide a means to estimate the unit sediment load $q_{s}$ (average value over flood or ebb tide) along the estuary with known $A$ and $P$. This is done in Table 1 for the Columbia River estuary (Oregon-Washington). Crosssection 1 at the Pacific Ocean entrance and cross-section $940 \mathrm{~km}$ upstream mark the lower reach of the estuary in which the sandy bed has a median grain diameter of $0.24 \mathrm{~mm}$ (O'Brien [9]). Noting that $s=\rho_{s} / \rho_{w}$, the relevant parameters are water density $\rho_{w}=1,010 \mathrm{~kg} \mathrm{~m}^{-3}$, sediment density $\rho_{s}=2,650 \mathrm{~kg} \mathrm{~m}^{-3}$, water kinematic viscosity $1.15 \times 10-6 \mathrm{~m}^{2} \mathrm{~s}^{-1}$, nominal tidal period $T=44,712 \mathrm{~s}$ and Manning's $n=$ 0.044 (Leopold et al. [10]). There is a general agreement between the measured and calculated unit loads, $q_{s m}$ and $q_{s c}$, respectively. However, the error $\varepsilon_{r}$ varies widely between $-52.1 \%$ and $259 \%$. The mean value of $29.6 \%$ is smaller and not unreasonably high, considering the interfering effects of tidal asymmetry, river discharge and the approximate method used to derive the loads (O’Brien [9]).

Table 1: Unit discharges and loads along the Columbia River estuary, Oregon/Washington.

\begin{tabular}{ccccccc}
\hline \hline $\begin{array}{c}\text { Cross- } \\
\text { section } \\
\text { No. }\end{array}$ & $\begin{array}{c}h \\
(\mathrm{~m})\end{array}$ & $\begin{array}{c}A \\
\left(\mathrm{~m}^{2}\right)\end{array}$ & $\begin{array}{c}P \\
\left(\mathrm{~m}^{3}\right)\end{array}$ & $\begin{array}{c}q_{s m} \\
\left(\mathrm{~m}^{2} \mathrm{~s}^{-1}\right)\end{array}$ & $\begin{array}{c}q_{s c} \\
\left(\mathrm{~m}^{2} \mathrm{~s}^{-1}\right)\end{array}$ & $\begin{array}{c}\varepsilon r \\
(\%)\end{array}$ \\
\hline 1 & 14 & $4.70 \times 10^{4}$ & $1.04 \times 10^{9}$ & $2.36 \times 10^{-3}$ & $1.37 \times 10^{-3}$ & -40.4 \\
2 & 12 & $4.00 \times 10^{4}$ & $1.38 \times 10^{9}$ & $1.18 \times 10^{-2}$ & $2.30 \times 10^{-2}$ & 100 \\
3 & 9 & $4.00 \times 10^{4}$ & $1.07 \times 10^{9}$ & $3.82 \times 10^{-3}$ & $6.67 \times 10^{-3}$ & 78.6 \\
4 & 8 & $4.90 \times 10^{4}$ & $1.09 \times 10^{9}$ & $5.18 \times 10^{-3}$ & $2.48 \times 10^{-3}$ & -50.9 \\
5 & 17 & $1.20 \times 10^{5}$ & $3.12 \times 10^{9}$ & $5.99 \times 10^{-3}$ & $2.98 \times 10^{-3}$ & -49.1 \\
6 & 7 & $5.60 \times 10^{4}$ & $1.20 \times 10^{9}$ & $1.43 \times 10^{-3}$ & $2.26 \times 10^{-3}$ & 61.7 \\
7 & 10 & $9.50 \times 10^{4}$ & $3.64 \times 10^{9}$ & $1.48 \times 10^{-2}$ & $5.18 \times 10^{-2}$ & 259 \\
8 & 6 & $6.40 \times 10^{4}$ & $1.07 \times 10^{9}$ & $1.27 \times 10^{-3}$ & $5.96 \times 10^{-4}$ & -52.1 \\
9 & 10 & $1.70 \times 10^{4}$ & $4.94 \times 10^{8}$ & $1.69 \times 10^{-2}$ & $9.86 \times 10^{-3}$ & -40.2 \\
\hline \hline
\end{tabular}

Data source: O'Brien [9].

\section{Equilibrium area}

The equilibrium cross-sectional area $A_{L e}$ of the entrance channel can be identified from the Escoffier diagram sketched in Fig. 5. It is defined by two relationships between area $A_{L}$ and maximum (flood or ebb) current velocity (amplitude) $U_{m}$. The hydraulic curve $H$ is determined by the tide at the mouth, channel length, depth, width and flow resistance, as well as the flood water storage capacity of the embayment of surface area $A_{B}$ upstream of the short channel. The sedimentary curve $S$ obtained from Eq. (6) can have a slightly negative or positive slope depending on the actual exponent in Eq. (6). Curve $S\left(\alpha_{s}=1\right)$ characterizes the equilibrium of the channel in the absence of load reduction. The intersection of $S\left(\alpha_{\mathrm{s}}=1\right)$ with $H$, at point $a$, defines pre-load-reduction value of $A_{L e}$. The respective velocity is $U_{m a}$. The second intersection at $a^{\prime}$ represents a channel at the threshold of instability in the sense that in the event of a sudden deposition of sediment the area and the current velocity will decrease, while flow resistance will increase. This in turn will encourage further deposition, area reduction and velocity 
reduction. Eventually this "downward spiraling" process will reduce the flow to the point at which the sand from the river or the littoral zone will effectively close the mouth. In the present case, since the pre-load-reduction channel is in stable equilibrium, we will not consider the condition at $a^{\prime}$ further.

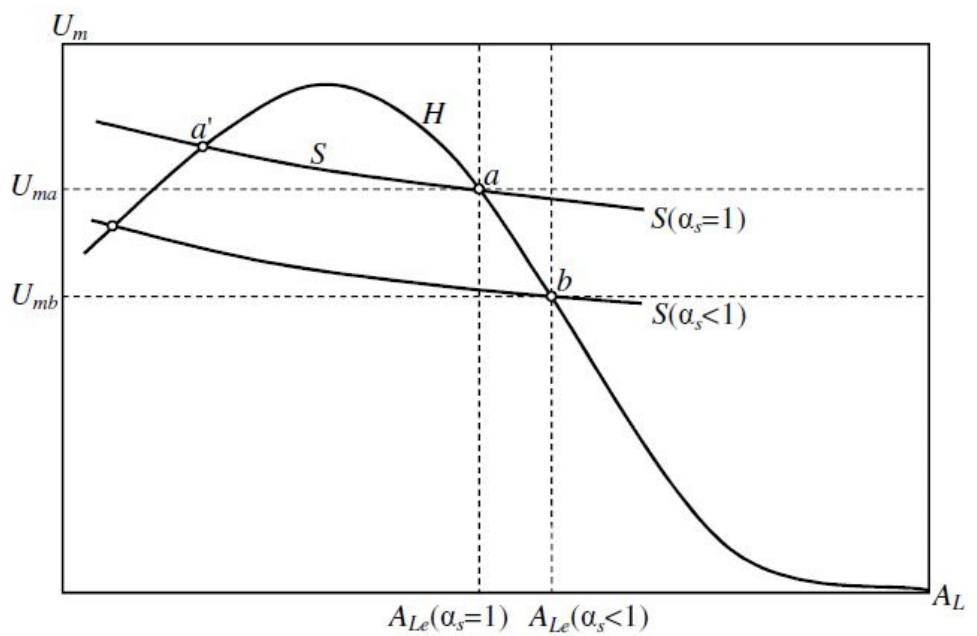

Figure 5: Escoffier diagram showing area-velocity relationships for short tidal channels.

We will consider large channels, with $m=1 / 3$ in Eq. (3), for which the $H$-curve is obtained from a conveniently linearized relationship between the hydraulic head-loss due to bed resistance and the current velocity, i.e. linearized Darcy headloss equation (e.g. Bruun [5]). The selected solution for the $H$-curve is one among several similar inlet hydraulics solutions obtained by solving the depth-integrated unsteady flow-continuity and momentum equations for short open channels (Bruun [5]). The solution assumes that the channel has no length, i.e. $x_{L}$ is a notional length that determines inertia of the mass of water in the channel and bed resistance to water movement. The tidally oscillating discharge $Q(t)$, where $t$ is time, depends on surface area $A_{B}$. This area is considered to rise and falls in unison, i.e. the surface is horizontal at all times as seawater enters as flood flow and leaves together with freshwater as ebb flow. The freshwater discharge $Q_{r}<<Q_{m}$, where the latter is the maximum tidal discharge during ebb (or flood) flow. Inasmuch as over the length of a typical estuary, tidal motion is in the form of a wave, i.e. its rise and fall are not in-phase, $A_{B}$ is an effective area consistent with in-phase water level oscillation.

The solution for the peak tidal velocity $U_{m}=Q_{m} / A_{0}$ is given by

$$
U_{m}=\frac{\sqrt{2} k_{0} A_{L}^{13 / 9}}{k_{4}} \sqrt{\sqrt{\left(1-\frac{k_{1}}{A_{L}}\right)^{4}+\left(\frac{k_{4}}{A_{L}^{22 / 9}}\right)^{2}}-\left(1-\frac{k_{1}}{A_{L}}\right)^{2}}
$$

where 


$$
k_{0}=a_{0} A_{B} \sigma ; k_{1}=\frac{x_{L} A_{B} \sigma^{2}}{g} ; k_{2}=\frac{a_{0} A_{B}}{2 x_{L}} ; k_{3}=\frac{2 g x_{L} n^{2}}{p^{4 / 3}} ; k_{4}=\frac{16}{3 \pi} k_{1} k_{2} k_{3}
$$

Application of Eqs (6) and (8) to real systems has been extensively explored and described elsewhere (e.g. Bruun [5]). For given tidal amplitude $a_{0}, U_{m}$ is sensitive to $A_{B}$ and channel length $x_{L}$, which together determine the relative roles of head-loss and inertia of the oscillating water mass in the channel.

The $S$-curve is obtained from Eqs (6) and (7). The area $A_{L e}$ is the equilibrium value at which the $H$ and $S$ curves intersect, i.e. the area which simultaneously satisfies the two equations. It is readily obtained by solving Eqs (6) - (9) after setting $A_{L}=A_{L e}$. The solution, implicit in $A_{L e}$, is

$$
A_{L e}=\left\{k_{5} A_{L e}^{16}\left(\sqrt{\left(\sqrt{\left(1-\frac{k_{1}}{A_{L e}}\right)^{4}+\left(\frac{k_{4}}{A_{L e}^{22 / 9}}\right)^{2}}-\left(1-\frac{k_{1}}{A_{L e}}\right)^{2}\right.}\right)^{6}\right\}^{1 / 7} \frac{1}{\left(\alpha_{s} Q_{s}\right)^{1 / 7}}
$$

where

$$
k_{5}=\frac{2^{9} K}{\pi^{6} p^{2}}\left(\frac{k_{0}}{k_{4}}\right)^{6}
$$

Equation (10) is solved iteratively for $A_{\text {Le }}$.

\section{Effect of load reduction at Matanzas Inlet}

Matanzas Inlet, the entrance of Matanzas River estuary (Fig. 6), is subject to semidiurnal tide with meso-tidal amplitude $a_{0}=0.75 \mathrm{~m}$. In the approximately $3 \mathrm{~km}$ long entrance channel, freshwater discharge $Q_{r}$ is negligible compared to a tidal mean discharge of $626 \mathrm{~m}^{3} \mathrm{~s}^{-1}$ (Powell et al. [4]). The channel is short compared to the tidal wave length where $g$ is the acceleration due to gravity and $\sigma=2 \pi / T$ is the tidal angular frequency. Taking $T=44,712 \mathrm{~s}$ and $h_{0}=2.6 \mathrm{~m}$ (Powell et al. [4]), $x_{L}$ is only $1.3 \%$ of the tidal wave length.

Referring to Fig. 5, as soon as sediment load is reduced, the point of intersection of the $S\left(\alpha_{s}=1\right)$-curve with the $H$-curve at $a$ denotes a hypothetical condition because the flow area cannot change instantaneously. In reality, adaptation of the area from $A_{L e}\left(\alpha_{s}=1\right)$ to $A_{L e}\left(\alpha_{s}<1\right)$ takes place only after a suitably long time as the interaction between flow and sediment transport gradually leads to a new equilibrium.

The dependence of $A_{L e}$ on $\alpha_{s}$ can be illustrated for Matanzas Inlet. We will take the year 1976 when the estuary had been undisturbed by a significant storm over the previous 12 years since Hurricane Dora in 1964. The relevant values are: $x_{L}=$ $3,000 \mathrm{~m}, A_{B}=3.5 \times 10^{6} \mathrm{~m}^{2}, p=0.369, n=0.0285, s=2.65$ and $v=10^{-6} \mathrm{~m}^{2} \mathrm{~s}^{-1}$ (Powell et al. [4]; Bruun [5]). The sediment load $Q_{s}=1.8 \times 10^{-4} \mathrm{~m}^{3} \mathrm{~s}^{-1}$ is obtained by calibration of Eq. (10) with respect to the 1976 channel cross-section area of $820 \mathrm{~m}^{2}$. We will consider the load reduction fraction as to range from 1 (no reduction) to 0.25 . 


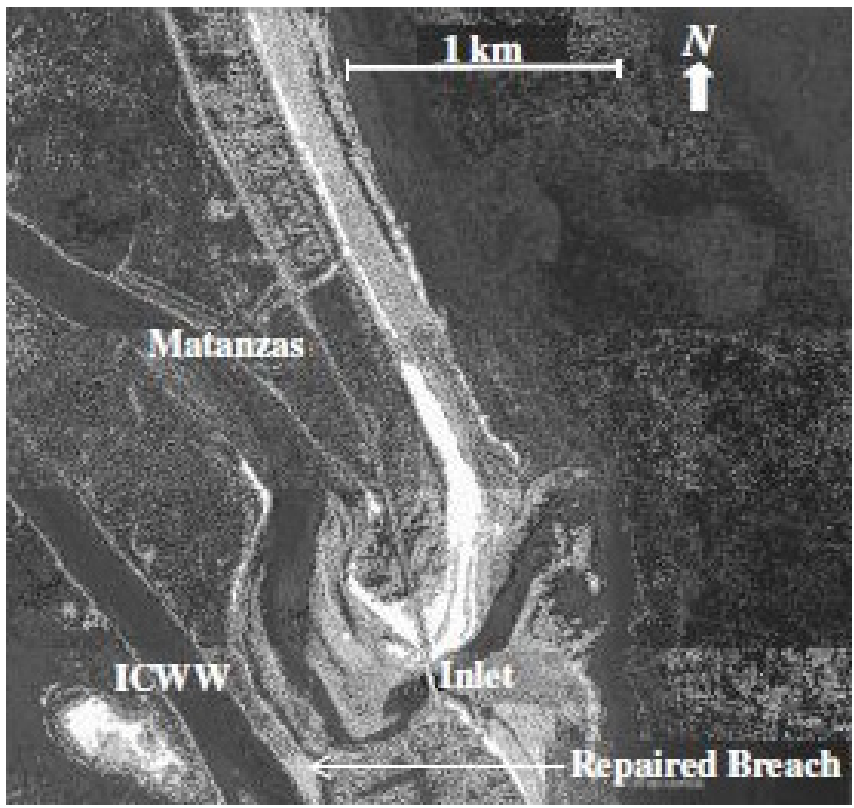

Figure 6: Matanzas Inlet, Florida (Google image).

In Fig. 7, for $\alpha_{s}=1,0.75,0.50$ and 0.25 the $H$-curve and the four $S$-curves intersect at $A_{L e}=820,864,928$ and $1,047 \mathrm{~m}^{2}$, respectively. In Fig. 8 the plot of Eq. (10) shows that, consistent with Fig. 5, $A_{L e}$ decreases with increasing load reduction. The pre-load reduction tidal prism $P=6.2 \times 10^{6} \mathrm{~m}^{3}$ obtained from Eq. (7), with $A_{L}=A_{L e}$, is close to $5.2 \times 10^{6} \mathrm{~m}^{3}$ at about the time of load reduction (Powell et al. [4]).

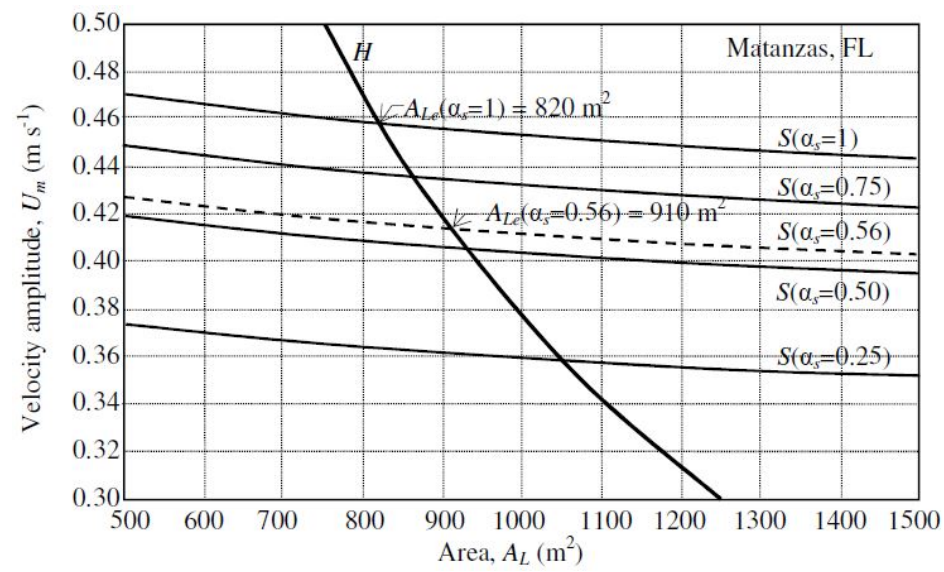

Figure 7: Effect of sediment load reduction on the equilibrium area of Matanzas Inlet. 


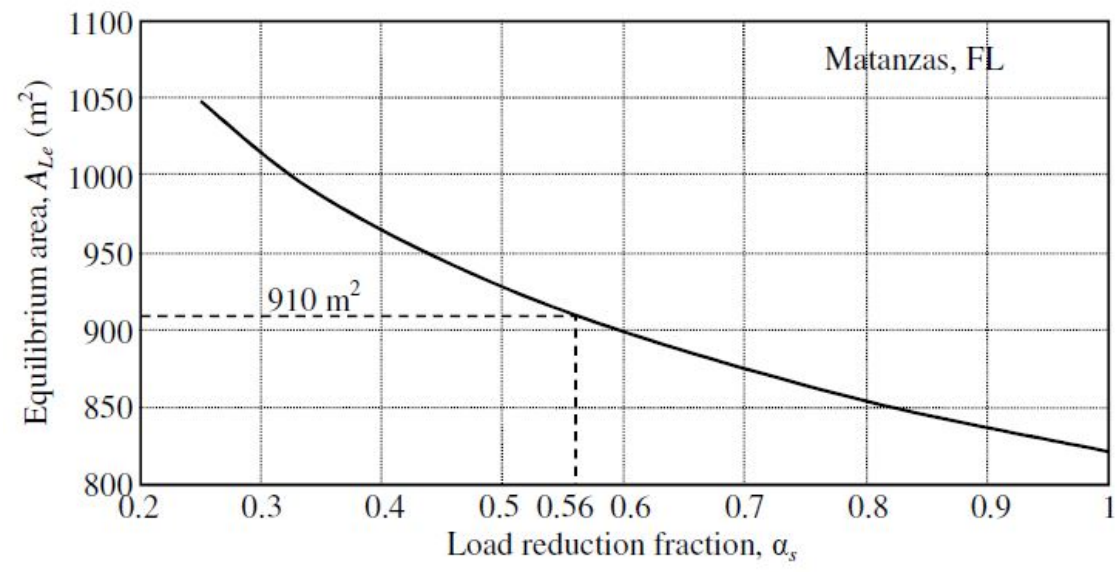

Figure 8: Variation of equilibrium area of the channel with load reduction fraction at Matanzas Inlet.

In 1976/77 a land breach between the estuary and the ICWW (Fig. 6) reportedly due to Hurricane Dora in 1964 was repaired (Hayter and Mehta [17]). This action is believed to have decreased sand movement in the entrance channel. A manifestation of load reduction was that, by 1995, a reasonably long (19 yr) duration for the entrance to achieve new equilibrium, $A_{L e}$ increased to $910 \mathrm{~m}^{2}$, i.e. by $11 \%$. This increase corresponds to a calculated volumetric discharge of $1 \times 10^{-4}$ $\mathrm{m}^{3} \mathrm{~s}^{-1}$, i.e. $\alpha_{s}=0.00010 / 0.00018=0.56$ (or $56 \%$ of the pre-load-reduction value) as the 19-year mean.

\section{Adaptation time}

As the method of Escoffier concerns equilibria only, for an estimation of the adaptation time relevant to load reduction we use a modified form of the approach of O'Connor et al. [18] developed for the effect of altering the tidal range on the estuary cross-section. Letting $N$ denote years, the rate of expansion of area $A_{L}$ due to bed erosion at the onset of load reduction $(N=0)$ is conveniently taken as

$$
\left(\frac{d A_{L}}{d N}\right)_{N=0}=M\left(q_{s}-\alpha_{s} q_{s}\right)=M q_{s}\left(1-\alpha_{s}\right)
$$

where $M$ is the erosion rate constant (e.g. Julien 2010). The expansion, at first rapid, gradually wanes until $A_{L}$ approaches a new equilibrium value $A_{e F}$ (corresponding to point $\mathrm{b}$ in Fig. 5). This can be expressed as

$$
A_{L}=\left(A_{e F}-A_{e I}\right)\left(1-e^{-K_{3} N}\right)+A_{e I}
$$

where subscript I denotes pre-load-reduction equilibrium. The time-constant $K_{3}$ is obtained from Eqs (12) and (13) as

$$
K_{3}=\frac{M q_{s}\left(1-\alpha_{s}\right)}{A_{e F}-A_{e I}}
$$


If after $N_{F}$ years the area reaches a value $(1-\varepsilon) A_{e F}$, which is close to $A_{e F}$ (using $\varepsilon=0.05$, a conveniently small fraction amounting to $A_{L}$ reaching $95 \%$ of $A_{e F}$ ), we get

$$
\frac{A_{L}}{A_{e I}}=\left(\frac{A_{e F}}{A_{e I}}-1\right)\left[1-e^{\left.-\left\{\frac{1}{N_{F}} \ln \left[\left(\frac{A_{e F}}{A_{e I}}-1\right)\left(\frac{A_{e F}}{A_{e I}}\right)\right]\right\}\right\}_{N}^{N}}\right]+1
$$

in which the term within the curly brackets is $K_{3}$. Finally,

$$
N_{F}=\frac{A_{e I}\left(\hat{A}_{e F}-1\right)}{M q_{s}\left(1-\alpha_{s}\right)} \ln \left(\frac{\hat{A}_{e F}-1}{\hat{A}_{e F} \varepsilon}\right)
$$

where, $\hat{A}_{e F}=A_{e F} / A_{e I}$ is used merely for compactness of the equation.

At Matanzas, $A_{e I}=820 \mathrm{~m}^{2}, h_{0}=2.8 \mathrm{~m}, A_{e F}=910 \mathrm{~m}^{2}, \alpha_{s}=0.56$ and $q_{s}=Q_{s h o} / A_{e I}$ $=6.14 \times 10^{-7} \mathrm{~m}^{2} \mathrm{~s}^{-1}$. Choosing $M=1.24$ as calibration value yields $N_{F}=6 \times 10^{8}$ s, i.e. 19 years (1976-1995). In general, $M$ depends on the grain size, bed features and channel geometry. Identification of this dependence for Matanzas requires threedimensional numerical modeling of sandy bed erosion in the channel.

\section{Concluding comments}

The analytic method provides a first-order estimate of the impact of reduction in sediment load (due to upstream freshwater withdrawal) on the cross-section of the tidal entrance channel. The degree of area expansion relative to the original and the time it takes to expand are both important in defining the protocol for water uptake, e.g. by pumping. The method is illustrated by application to Matanzas Inlet. Although in general numerical modeling is a powerful tool to assess quantitative effects of load reduction, the described approach is especially useful for preliminary estimations of impacts at tidal entrances for which the morphodynamic database is limited.

\section{References}

[1] Neubauer, C.P., Hall, G.B., Lowe, E.F., Robison, E.C., Hupalo, R.B. and Keenan, L.W., Minimum flows and levels method of the St. Johns River Water Management District, Florida, USA, Environmental Management, 42, 1101-1114, 2008.

[2] Escoffier, F.F., The stability of tidal inlets, Shore and Beach, 8(4), 114-115, 1940.

[3] O'Brien, M.P. and Dean, R.G., Hydraulics and sedimentary stability of coastal inlets, Proceedings of the 13th International Conference on Coastal Engineering, ASCE, 761-780, 1972.

[4] Powell, M.A., Thieke, R.J., and Mehta, A.J., Morphodynamic relationships for ebb and flood delta volumes at Florida's tidal entrances, Ocean Dynamics, 56, 295-307, 2006.

[5] Bruun, P., Stability of Tidal Inlets: Theory and Engineering, Elsevier, 1978. 
[6] Julien, P.Y. Erosion and Sedimentation, 2nd. Ed., Cambridge, 2010.

[7] O'Brien, M.P., Equilibrium flow areas of inlets on sandy coasts. Journal of the Waterways, Harbors and Coastal Engineering Division of ASCE, 95(1), 43-52, 1969.

[8] Hughes, S.A., Equilibrium cross sectional area at tidal inlets, Journal of Coastal Research, 18(1), 160-174, 2002.

[9] O'Brien, M.P., Field and laboratory studies on navigation channels of the Columbia River estuary, Report HEL 24-4, Hydraulic Engineering, University of California, Berkeley, 1971.

[10] Leopold, L.B., Wolman, M.G. and Miller J.P., Fluvial Processes in Geomorphology, W.H. Freeman, 1964.

[11] Wicker, C.F., The prototype and model Delaware Estuary, Proceedings of the 6th General Meeting of IAHR, The Hague, paper A12, 1-18, 1955.

[12] Nichols, M.M. and Biggs, R.B., Estuaries, In: Coastal Sedimentary Environments, Davis R.A. ed., Springer-Verlag, 77-186, 1978.

[13] Goodwin, C.R., Emmett, E.W. and Glenne, B., Tidal study of three Oregon estuaries, Technical Bulletin, Engineering Experiment Station, Oregon State University, Corvallis, 1970.

[14] Langbein, W.B., The hydraulic geometry of a shallow estuary, Bulletin of the International Association of Scientific Hydrology, 8(3), 84-94, 1963.

[15] Stelzenmuller, W.B., Tidal characteristics of two estuaries in Florida, Journal of Waterways and Harbors Division, ASCE, 91(1), 25-36, 1965.

[16] Alkhalidi, M., Sedimentary equilibrium and morphology of inlets and estuaries, Ph.D. thesis, University of Florida, Gainesville, 2004.

[17] Hayter, E.J. and Mehta, A.J., Verification of changes in flow regime due to dike breakthrough closure. Proceedings of Coastal Structures'79, ASCE, New York, 729-746, 1979.

[18] O’Connor, B., Nicholson, J. and Rayner, R., Estuary geometry as a function of tidal range, Proceedings of the 22nd International Conference on Coastal Engineering, ASCE, New York, 3050-3062, 1991. 